\title{
Non-Surgical and Non-Radioiodine Techniques for Ablation of Benign Thyroid Nodules: Consensus Statement and Recommendation*
}

\author{
Authors \\ Joachim Feldkamp1, F. Grünwald², Markus Luster ${ }^{3}$, Kerstin Lorenz ${ }^{4}$, Christian Vorländer ${ }^{5}$, Dagmar Führer
}

\section{Affiliations}

1 Department of General Internal Medicine, Endocrinology and Diabetes, Infectious Diseases, Klinikum Bielefeld, Bielefeld, Germany

2 Department of Nuclear Medicine, Johann Wolfgang Goethe University Hospital Frankfurt, Frankfurt am Main, Germany

3 Department of Nuclear Medicine, University Hospital Marburg, Marburg, Germany

4 Departments of Visceral, Vascular and Endocrine Surgery, University Hospital Martin Luther University Halle-Wittenberg, Halle (Saale), Germany

5 Department of Endocrine Surgery, Bürgerhospital Frankfurt, Frankfurt am Main, Germany

6 Department of Endocrinology, Diabetes and Metabolism, University Hospital Essen, Essen, Germany

\section{Key words}

radiofrequency ablation, microwave ablation, laser ablation, high frequency ultrasound ablation
received $\quad 09.10 .2018$
revised $\quad 30.11 .2019$
accepted $\quad 03.12 .2019$

\section{Bibliography}

DOI https://doi.org/10.1055/a-1075-2025

Published online: 7.1.2020

Exp Clin Endocrinol Diabetes 2020; 128: 687-692

(c) J. A. Barth Verlag in Georg Thieme Verlag KG Stuttgart .

New York

ISSN 0947-7349

\author{
Correspondence \\ Joachim Feldkamp \\ Department of General Internal Medicine, Endocrinology \\ and Diabetes, Infectious Diseases \\ Klinikum Bielefeld \\ Teutoburger Straße 50 \\ 33604 Bielefeld \\ Germany \\ Tel.: +495215813 501, Fax:+495215813599 \\ joachim.feldkamp@klinikumbielefeld.de
}

\section{ABSTRACT}

Thyroid nodules and cysts are frequently diagnosed in Germany with a prevalence of about $20 \%$ in young adults reaching up to $70 \%$ in older adults. Surgery is the standard treatment of symptomatic nodules, nodules with suspicion of malignancy and thyroid cancer. Radioiodine treatment is applied for autonomously functioning nodules. During the last years new non-surgical and non-radioiodine techniques have been introduced to treat thyroid nodules. These techniques include ethanol/polidocanol treatment, radiofrequency, microwave, and laser ablation, and high frequency ultrasound ablation. A significant reduction in nodule size could be documented for these techniques in several studies, but long-term outcome data are missing. Until now, there is no general consensus regarding the appropriate indications for these methods. For this reason, the Thyroid Section (German Society for Endocrinology), the Thyroid Working Committee (German Society for Nuclear Medicine), and the German Association of Endocrine Surgeons (CAEK) for the German Society of General and Visceral Surgery (DGAV) reviewed the respective literature, discussed the pro and cons and developed a consensus statement and recommendation to help physicians and patients in their decision making.

\footnotetext{
Consensus statement and recommendation of the Thyroid Section (German Society for Endocrinology), the Thyroid Working Committee (German Society for Nuclear Medicine), and the German Association of Endocrine Surgeons (CAEK) for the German Society of General and Visceral Surgery (DGAV).
} 
Thyroid nodules are increasingly diagnosed with the use of ultrasound worldwide. In Germany, thyroid nodules are frequent with a prevalence of about $20 \%$ in young adults and up to $70 \%$ in the elderly population [1-3]. Moderate to severe iodine deficiency has contributed to this high prevalence of thyroid nodules in the past. Most of these nodules are benign. In contrast, thyroid malignancy is rare with $<7.000$ newly diagnosed cases every year in Germany. For decades, thyroid surgery has been, and still is, the routine treatment for symptomatic nodular thyroid disease and thyroid cancer, while radioiodine therapy is generally used to treat autonomously functioning nodules.

Starting in the early 1990's the first studies on ethanol treatment of thyroid nodules have been reported by an Italian group [4]. In the following three decades other methods have been developed for non-surgical and non-radioiodine ablation of thyroid nodules: radiofrequency ablation, microwave ablation, laser ablation, and high frequency ultrasound ablation. These methods are used evermore in different indications.

There is some uncertainty in the scientific community concerning the indication, efficacy, and treatment outcome of these frequently called / so-called "alternative" ablation techniques, even though lack of comparative studies with established treatment methods precludes the use of the term "alternative". However, since these methods are increasingly used by different institutions and demanded by patients in different indications, there is a need for information for physicians treating patients with thyroid disease.

Therefore, the Thyroid Section of the German Society for Endocrinology, the Thyroid Working Committee of the German Society for Nuclear Medicine, and the German Association of Endocrine Surgeons agreed to develop recommendations for the application of these ablation techniques.

\section{Working Methods and Grading of Recommendations}

The starting point of this process was the Annual Meeting of the Thyroid Section of the German Society for Endocrinology in Bremen in 2017, hosted by Prof. Klaudia Brix of the Jacobs University Bremen. Following this meeting, the three groups continued in engaged discussion resulting in the statement and recommendations published in this article. A preliminary document was generated by one of the authors (J. F.) and critically reviewed by the members of the working group. Positions were discussed via electronic communication until final consensus was found. The quality of evidence found in the literature and the strengths of recommendations were elaborated according to the Grading of Recommendations, Assessment, Development, and Evaluation (GRADE) system [5].

Before considering the different non-surgical and non-radioiodine local-ablative therapies, there are some recommendations with general validity for all procedures:

\section{Recommendations}

1) The presence of a sonographically visible nodule per se without symptoms or hyperfunction and without suspicion or evidence of malignancy is no indication for any therapeutic intervention.
There is no evidence that the patient may benefit from the therapy. Watchful waiting may be sufficient [6].

Strong recommendation moderate quality of evidence

2) If treatment of a thyroid nodule is planned with surgical/nonradioiodine ablation therapy, fine needle aspiration cytology is required prior to treatment in the following situations and must show benign cytology (according to Bethesda class I, II) with reliable/sufficient diagnostic value (at least 6 groups of follicular cells with $10-15$ cells each).

- In nodules with low risk of malignancy (completely cystic, mixed cystic and solid isoechoic, spongiform, isoechoic appearance, nodule with smooth margins) a single fine needle biopsy is required.

- In nodules with higher probability of malignancy (intermediate risk according to TIRADS, EU-TIRADS), two fine needle biopsies are necessary [7, 8].

In contrast, autonomously functioning nodules do not require a fine needle biopsy.

Strong recommendation, moderate-quality of evidence

3) Pre-and post-interventional, all patients who are planned for a local-ablative procedure must be examined as accurately as patients who undergo surgery. Calcitonin-screening is mandatory as is laryngoscopy prior to and after the procedure.

Strong recommendation, moderate quality of evidence

4) The performing institution must be able to treat complications (bleeding, infection) in case of Radiofrequency ablation (RFA), Percutaneous Microwave Ablation (PMWA), and Laser Thermal Ablation (LTA).

Strong recommendation, moderate quality of evidence

We strongly recommend against non-surgical treatment of thyroid nodules with suspicion or evidence for malignancy and their metastases. These patients should undergo treatment following current international guidelines [9].

Strong recommendation, moderate quality of evidence

An exception may be the treatment of local recurrence and lymph node metastases in a palliative situation, but this consensus statement addresses the therapy of benign nodules and so we refrain from further comments.

\section{Ethanol-/Polidocanol-Ablation}

The percutaneous ultrasound guided instillation of sterile $95 \%$ ethanol into thyroid nodules leads to cellular dehydration, thrombosis of small vessels, protein denaturation, cellular coagulation necrosis and subsequent reactive tissue fibrosis [4] with reduction in nodule volume over time. This technique has mostly been used for the treatment of autonomously functioning nodules and in the treatment of cysts and cystic nodules. Long-term cure in the treatment of toxic nodules could be achieved in only $70 \%$ of the cases $[10,11]$. Treatment of recurrent thyroid cysts with ethanol leads to better results than simple evacuation of cystic fluid [12]. In small case series, treatment with ethanol resulted in a mean nodule volume reduction of $51 \%$ in one series $(n=30)$ and in $31 \pm 11 \%$ at least $50 \%$ in another study $(n=52)[13,14]$. Reported adverse events were pain, transient hyperthyroidism, transient and permanent recurrent nerve palsy, permanent ipsilateral facial dysaesthesia, and paranodular fibrosis with need of surgery. 


\section{Recommendations}

Indications for ethanol-/polidocanol ablation may be:

- Recurrent cysts; in case of pure cysts, polidocanol may be used alternatively

- Benign thyroid nodules with large cystic parts

- Autonomous thyroid nodules in patients with multimorbidity who are not amenable to conventional therapies (radioiodine therapy, surgery)

- Autonomous thyroid nodules in patients who refuse conventional therapies

Weak recommendation, low or very low quality of evidence

\section{Thermal Ablation Techniques}

Over more than four decades thermal techniques have been used to ablate tissue in different organs (e. g. in liver, kidney, prostate, bone and lung) $[15,16]$. Subsequently, various thermal ablation techniques were introduced for the treatment of thyroid nodules:

- Radiofrequency ablation

- Microwave ablation

- Laser ablation

- High freqency ultrasound ablation

\section{Radiofrequency Ablation (RFA)}

Radiofrequency ablation uses an alternating electric current with frequencies usually below $900 \mathrm{KHz}$. An electrode needle is connected to a radiofrequency generator. The treatment induces excitation of electrons with a subsequent increase of temperature at the active site of the probe. This leads to thermal tissue necrosis. Developing microbubbles have an additional mechanical damaging effect. Conducting heat leads to slow growing temperatures in more remote tissue. This mechanism is responsible for most of the therapeutic effect of RFA. If monopolar RFA systems are used, grounding pads are necessary since the electric current runs through the body trunk. In bipolar probes the electric current is limited to a small area surrounding the active tip of the probe. The use of bipolar probes is safer in patients with implanted electrical devices such as pacemakers. The use of cooled probes reduces the risk of skin burning and destruction of tissue along the shaft of the probe.

In 2006, the first report using RFA in 30 patients with thyroid nodules was published [17]. In the last decade more than two thousand patients have been treated by RFA. The expertise in the field of RFA is concentrated in a few centers. Most of the experience derives from two centers in South Korea and China. Reductions of nodule volume were reported to range from $50-80 \%$ after 6 months and $79-90 \%$ after two years of follow-up [18-22]. In a large series of patients ( $n=277$, monopolar RFA) from Austria the overall nodule volume reduction rate at 3 and 12 months was $68 \pm 16 \%$ and $82 \pm 13 \%$, respectively [18]. Autonomous function was documented in 32 patients from this series. $84 \%$ of these patients were biochemically cured after one year.

There are only few data available regarding the long-term outcome in patients treated with RFA. Sim et al. reported a nodule regrowth (defined as more than $50 \%$ increase in volume) in $24.1 \%$ of
54 patients with a median follow-up time of $39.9 \pm 17.5$ months [23]. They concluded that re-growth was largely due to nodule margins that have not been treated sufficiently [23].

Complications of the procedure include injury of the recurrent nerve with voice changes (nearly all were reported to be transient), but laryngoscopy was not systematically done in all studies limiting the interpretation of these data. Brachial plexus damage, nodule rupture, change in thyroid function (mostly transient), bleeding, subsequent hematoma, cough, vomiting, vago-vagal reaction, skin burns and infections have also been reported in a small number of cases. Pain is usually present and is mostly treated with analgetics, if necessary.

\section{Percutaneous Microwave Ablation (PMWA)}

Microwave systems use an alternating electromagnetic field that produces a power of $1-150 \mathrm{~W}$ at $950 \mathrm{MHz}$ or $2450 \mathrm{MHz}$. Heat is generated as the alternating field interacts with tissue water and ions leading to local high temperature (up to more than $100^{\circ}$ Celsius) and ablation zones are usually larger than ablation zones induced by RFA [24-26]. In tumors with rich blood supply the perfusionmediated heat-sink effect may lead to smaller therapeutic effects. PMWA is less affected than RFA by this effect [27]. Cooling systems are used to reduce the heat along the antenna to avoid skin burning and destruction of tissue along the shaft of the probe. Microwave technique does not require grounding pads. A disadvantage of PWMA is that the microwave power has to be carried in coaxial cables which are thicker in diameter than the wires used for RFA.

In 2012 Feng et al. reported the first 11 patients treated by PMWA with a relative volume reduction of the nodules of $45.99 \pm 29,99 \%$ after one year follow-up [28]. Thereafter, only few studies with PMWA in thyroid nodules have been published. Mean reduction of nodule volume has been reported between 45 to $65 \%$ shortly after the first report $[29,30]$.

Piu et al. treated a large number of 435 patients with a mean volume reduction rate of $90 \%$ after one year in nodules with an average volume of $13.07 \pm 0.95 \mathrm{~mL}$ before treatment, and $1.14 \pm$ $0.26 \mathrm{~mL}$ at 12-months follow-up [31]. Wu et al. documented a decrease in mean nodule volume from $8.56 \pm 4.21 \mathrm{~mL}$ to $1.05 \pm 1.05 \mathrm{~mL}$ in 100 patients with 121 nodules one year after treatment [32]. Adverse effects of PWMA do not differ significantly from those of RFA.

\section{Laser Thermal Ablation (LTA)}

Laser light is used to increase temperature up to $>60^{\circ} \mathrm{C}$ in the target lesion leading to tissue necrosis and subsequent fibrosis. Via silical optical fibers the laser light is conducted into the lesion. Laser diodes or ND:YAG (neodymium: yttrium aluminium garnet) are the source of energy. Up to four needles are used simultaneously with energy delivered over a time of 5-15 min [33].

A Danish group treated the first patients with laser ablation with a median nodule volume of $10.0 \pm 7.9 \mathrm{~mL}$. Six months after treatment a volume reduction to $5.4 \pm 5.1 \mathrm{~mL}$ could be documented (mean volume reduction $46 \%$ ) [34]. A longer follow-up of three years demonstrated a mean volume decrease of $47.8 \%$ in a series of 122 patients with quite large nodules (mean initial volume $23.2 \pm 21.3 \mathrm{~mL}$ ). $\ln 9 \%$ of the patients the nodules regrew over base- 
line size after 3 years. In 78 patients with cold nodules a mean volume reduction of $51 \%$ could be seen. After 12-96 months (mean 36) 21 of these patients underwent thyroid surgery because LTA treatment had an unsatisfactory result [35]. In seven patients with toxic nodules, thyroid function was normalized three months after LTA [36]. After a follow-up of 45 months a mean volume reduction of $85 \%$ could be documented in 110 patients with cystic lesions causing local discomfort. Nineteen of these patients (17.3\%) underwent surgery after LTA [37].

\section{Recommendations}

Indications for thermal ablation techniques may be:

\section{- Symptomatic nodules}

A symptomatic nodule is defined by symptoms caused by the nodule including dysphagia, feeling of oppression, cough, and pain. Other causes of these symptoms have to be excluded prior to therapy. A scoring system for a subjective evaluation of the severity of the complaints should be used [38].

\section{- Benign nodules with cosmetic indication}

Prerequisite: Visible nodule/swelling

A validated scoring system for subjective evaluation should be used [38].

\section{- Autonomously functioning nodules}

- Prerequisite: relevant functional activity $(\mathrm{TSH}<0.3 \mathrm{mU} / \mathrm{ml}$ without therapy with thyroid hormones) proven by $99 \mathrm{mTc}$ pertechnetate/ ${ }^{123}$ I scan (uptake under suppression, if necessary)

- In selected patients who are not suitable for surgery or radioiodine therapy and are at risk for iodine contamination with iodine containing contrast agents potentially resulting in heart arrhythmias (especially atrial fibrillation). If patients in need for therapy refuse conventional therapies (surgery, radioiodine therapy).

Weak recommendation, low or very low quality of evidence

\section{High frequency ultrasound ablation (HIFU)}

High frequency ultrasound ablation uses the heat induced by focused ultrasound beams applied by ultrasound probes outside the body. The temperature reaches up to $85^{\circ} \mathrm{C}$ in the treatment area, resulting in local tissue destruction with necrosis [39]. Due to the heat, water vaporises and bubbles are formed. With multiple bubbles developing and expanding, mechanical damage occurs to the cell structure of nearby cells.

The ultrasound treatment is computer aided and the nodule is automatically subdivided in multiple ablation units with a size of approximately $5 \mathrm{~mm}$ (width) $\times 7 \mathrm{~mm}$ (thickness). After a treatment pulse of $8 \mathrm{~s}$, a cooling phase of about $40 \mathrm{~s}$ is required before the next pulse can be applied. The system respects a margin to structures at risk, such as trachea, carotid artery and skin. The procedure is painful and requires concomitant analgesic therapy [40].

Until now, there are limited data on the long-term follow-up of patients treated with HIFU. In small case series, the reduction of nodule volume ranges from $55 \%$ after three months to $68 \%$ after 12 months [41, 42]. In a larger series of 108 patients undergoing a single treatment, the median relative volume reduction of the nodules was $68.66 \pm 18.48 \%$ after one year and $70.41 \pm 17.39 \%$ after two years. An increase of nodule size of more than $4.5 \%$ was documented in $20.4 \%$ of the cases from 12 to 24 months. Smaller tumor volume was significantly associated with better treatment success [43]. A direct comparison of HIFU with conventional radioiodine therapy (RAI) resulted in a similar reduction of nodule volume but in a significantly better functional result in patients treated with radioiodine. A scintigraphic response was achieved in $94 \% \mathrm{RAI}-$ treated patients compared to $53 \%$ HIFU-treated patients [44].

\section{Recommendations}

Indication for HIFU may be:

\section{- Small symptomatic nodules ( $<15 \mathrm{~mL})$}

A symptomatic nodule is defined by symptoms caused by the nodule such as dysphagia, feeling of compression, cough, and pain. Other causes of these symptoms have to be excluded prior to therapy. A scoring system (numeric rating scale, visual analogue scale, verbal rating scale) for a subjective evaluation of the severity of the complaints should be used.

\section{- Benign nodules with cosmetic indication}

Prerequisite: Visible nodule/cervical swelling

A validated scoring system for subjective evaluation should be used [38].

\section{- Autonomously functioning nodule/toxic adenoma}

If conventional therapy (radioiodine therapy, surgery,) is judged imperiling for the patient, e. g. in rare cases of multimorbidity and/or patients with iodine excess (therapy with amiodarone, recent use of iodine containing contrast agents) who are not suitable for surgery or if patients in need of treatment refuse conventional therapies (surgery, radioiodine therapy, antithyroid drugs).

Weak recommendation, low or very low quality of evidence

Non-surgical and non-radioiodine local ablative therapies are not indicated:

- In nodules demonstrating sonographic features with high risk of malignancy (TIRADS and EU-TIRADS category 5) even with benign cytology (2-5\% false negative results)

- Suspicious cervical lymph nodes

- Follicular neoplasia in cytology (exception: autonomous adenoma, proven by radionuclide scan)

- Proven malignancy

- High risk of malignancy (history of external beam irradiation of the neck, history of two or more family members with thyroid carcinoma), suspicious molecular markers in fine needle biopsy specimen (i.e., BRAFV600E mutation)

Strong recommendation, low quality of evidence

\section{Patient Information}

Prior to a therapy with local ablative techniques informed consent has to be obtained from the patient after detailed information. This should include chances of cure in detail, possible adverse events and alternative therapeutic procedures, especially the convention- 
al approaches using surgery or radioiodine therapy, and impeded ultrasound follow-up due to treatment induced tissue alterations obscuring ultrasound evaluation. The patient should to be informed, that long-term data for all other forms of local ablative treatment are missing. Only for RFA, follow-up data over a period of 5 years are available.

The patient must be informed that the risk for complications due to prior local ablative therapy might be higher if thyroid surgery is required at a later point of time, particularly if the capsule of the nodule is affected.

Some scientific societies have already incorporated the above mentioned ablation techniques into their guidelines for the treatment of thyroid nodules or have given specific recommendations for their application $[9,45-47]$.

All three German scientific societies involved in this paper are distinctly aware that scientific progress may change the view on the methods investigated and that this statement reflects the state of scientific knowledge as in summer of 2019.

\section{Acknowledgement}

We are highly grateful to Prof. Dr. Klaudia Brix, Jacobs University Bremen, for arranging and hosting the consensus conference on non-surgical/non-radioiodine ablation of thyroid nodules as part of the annual meeting of the Thyroid Section of the German Endocrine Society.

\section{Conflict of Interest}

No conflict of interest has been declared by the authors.

\section{References}

[1] Volzke H, Ludemann J, Robinson DM et al. The prevalence of undiagnosed thyroid disorders in a previously iodine-deficient area. Thyroid : Official Journal of The American Thyroid Association 2003; 13: 803-810. doi: $10.1089 / 105072503768499680$

[2] Reiners C, Wegscheider K, Schicha $\mathrm{H}$ et al. Prevalence of thyroid disorders in the working population of Germany: Ultrasonography screening in 96,278 unselected employees. Thyroid : Official Journal of The American Thyroid Association 2004; 14: 926-932. doi:10.1089/thy.2004.14.926

[3] Meisinger C, Ittermann T, Wallaschofski H et al. Geographic variations in the frequency of thyroid disorders and thyroid peroxidase antibodies in persons without former thyroid disease within Germany. European Journal of Endocrinology 2012; 167: 363-371. doi:10.1530/ eje-12-0111

[4] Livraghi T, Paracchi A, Ferrari C et al. Treatment of autonomous thyroid nodules with percutaneous ethanol injection: Preliminary results. Work in progress. Radiology 1990; 175: 827-829. doi:10.1148/ radiology.175.3.2188302

[5] Swiglo BA, Murad MH, Schunemann H] et al. A case for clarity, consistency, and helpfulness: state-of-the-art clinical practice guidelines in endocrinology using the grading of recommendations, assessment, development, and evaluation system. The Journal of Clinical Endocrinology and Metabolism 2008; 93: 666-673. doi:10.1210/jc.2007-1907
[6] Bartsch DK, Luster M, Buhr H] et al. Indications for the Surgical Management of Benign Goiter in Adults. Dtsch Arztebl Int 2018; 115 : 1-7. doi:10.3238/arztebl.2018.0001

[7] Russ G, Bonnema SJ, Erdogan MF et al. European Thyroid Association Guidelines for ultrasound malignancy risk stratification of thyroid nodules in adults: The EU-TIRADS. European Thyroid Journal 2017; 6 9. doi:10.1159/000478927

[8] Tessler FN, Middleton WD, Grant EG. Thyroid Imaging Reporting and Data System (TI-RADS): A User's Guide. Radiology 2018; 287: 29-36. doi:10.1148/radiol.2017171240

[9] Haugen BR, Alexander EK, Bible KC et al. 2015 American Thyroid Association Management Guidelines for Adult Patients with Thyroid Nodules and Differentiated Thyroid Cancer: The American Thyroid Association Guidelines Task Force on Thyroid Nodules and Differentiated Thyroid Cancer. Thyroid : Official Journal of The American Thyroid Association 2016; 26: 1-133 .doi:10.1089/thy.2015.0020

[10] Lippi F, Ferrari C, Manetti L et al. Treatment of solitary autonomous thyroid nodules by percutaneous ethanol injection: results of an Italian multicenter study. The Multicenter Study Group. The Journal of Clinical Endocrinology and Metabolism 1996; 81: 3261-3264. doi:10.1210/jcem.81.9.8784080

[11] Monzani F, Caraccio N, Goletti O et al. Treatment of hyperfunctioning thyroid nodules with percutaneous ethanol injection: Eight years' experience. Experimental and clinical endocrinology \& diabetes: Official Journal, German Society of Endocrinology [and] German Diabetes Association. 1998. 106: Suppl 4 S54-S58. doi:10.1055/s-0029-1212058

[12] Bennedbaek FN, Hegedus L. Treatment of recurrent thyroid cysts with ethanol: A randomized double-blind controlled trial. The Journal of Clinical Endocrinology and Metabolism 2003; 88: 5773-5777. doi:10.1210/jc.2003-031000

[13] Zingrillo M, Collura D, Ghiggi MR et al. Treatment of large cold benign thyroid nodules not eligible for surgery with percutaneous ethanol injection. The Journal of Clinical Endocrinology and Metabolism 1998; 83: 3905-3907. doi:10.1210/jcem.83.11.5257

[14] Felício JS, Conceição AMS, Santos FM et al. Ultrasound-guided percutaneous ethanol injection protocol to treat solid and mixed thyroid nodules. Frontiers in Endocrinology 2016; 7. doi:10.3389/ fendo.2016.00052

[15] Crocetti L, de Baere T, Lencioni R. Quality improvement guidelines for radiofrequency ablation of liver tumours. Cardiovascular and Interventional Radiology 2010; 33: 11-17. doi:10.1007/s00270-009-9736-y

[16] Grünwald F. Alternative Technik bei gutartigen Befunden. Schilddrüse 2017; Lehmanns Media; Berlin

[17] Kim YS, Rhim H, Tae K et al. Radiofrequency ablation of benign cold thyroid nodules: Initial clinical experience. Thyroid : Official Journal of The American Thyroid Association 2006; 16: 361-367. doi:10.1089/ thy.2006.16.361

[18] Dobnig H, Amrein K. Monopolar radiofrequency ablation of thyroid nodules: A Prospective Austrian single-center study. Thyroid : Official Journal of The American Thyroid Association 2017; 28: 472-480. doi:10.1089/thy.2017.0547

[19] Jeong WK, Baek JH, Rhim H et al. Radiofrequency ablation of benign thyroid nodules: safety and imaging follow-up in 236 patients. European Radiology 2008; 18: 1244-1250. doi:10.1007/s00330-0080880-6

[20] Deandrea M, Limone P, Basso E et al. US-guided percutaneous radiofrequency thermal ablation for the treatment of solid benign hyperfunctioning or compressive thyroid nodules. Ultrasound in Medicine \& Biology 2008; 34: 784-791. doi:10.1016/j.ultrasmedbio.2007.10.018 
[21] Lim HK, Lee JH, Ha E] et al. Radiofrequency ablation of benign non-functioning thyroid nodules: 4-year follow-up results for 111 patients. European Radiology 2013; 23: 1044-1049. doi:10.1007| s00330-012-2671-3

[22] Spiezia S, Garberoglio R, Milone F et al. Thyroid nodules and related symptoms are stably controlled two years after radiofrequency thermal ablation. Thyroid : Official Journal of The American Thyroid Association 2009; 19: 219-225. doi:10.1089/thy.2008.0202

[23] Sim JS, Baek JH, Lee J et al. Radiofrequency ablation of benign thyroid nodules: Depicting early sign of regrowth by calculating vital volume. International journal of hyperthermia : The Official Journal of European Society for Hyperthermic Oncology, North American Hyperthermia Group 2017; 33: 905-910. doi:10.1080/02656736.2017.1309083

[24] Andreano A, Huang Y, Meloni MF et al. Microwaves create larger ablations than radiofrequency when controlled for power in ex vivo tissue. Medical Physics 2010; 37: 2967-2973. doi:10.1118/1.3432569

[25] Lubner MG, Brace CL, Hinshaw JL et al. Microwave tumor ablation: mechanism of action, clinical results, and devices. Journal of Vascular and Interventional Radiology: JVIR 2010; 21: S192-S203. doi:10.1016/j.jvir.2010.04.007

[26] Vorlander C, David Kohlhase K, Korkusuz Y et al. Comparison between microwave ablation and bipolar radiofrequency ablation in benign thyroid nodules: Differences in energy transmission, duration of application and applied shots. International Journal of Hyperthermia : the Official Journal of European Society for Hyperthermic Oncology, North American Hyperthermia Group 2018; 35: 216-225. doi:10.1080 /02656736.2018.1489984

[27] Wright AS, Sampson LA, Warner TF et al. Radiofrequency versus microwave ablation in a hepatic porcine model. Radiology 2005; 236: 132-139. doi:10.1148/radiol.2361031249

[28] Feng B, Liang P, Cheng Z et al. Ultrasound-guided percutaneous microwave ablation of benign thyroid nodules: Experimental and clinical studies. European Journal of Endocrinology 2012; 166: 1031-1037. doi:10.1530/eje-11-0966

[29] Yue W, Wang S, Wang B et al. Ultrasound guided percutaneous microwave ablation of benign thyroid nodules: Safety and imaging follow-up in 222 patients. European Journal of Radiology 2013; 82: e11-e16. doi:10.1016/j.ejrad.2012.07.020

[30] Heck K, Happel C, Grunwald F et al. Percutaneous microwave ablation of thyroid nodules: Effects on thyroid function and antibodies. International journal of hyperthermia : The Official journal of European Society for Hyperthermic Oncology, North American Hyperthermia Group 2015; 31: 560-567. doi:10.3109/02656736.2015.1032371

[31] Liu Y], Qian LX, Liu D et al. Ultrasound-guided microwave ablation in the treatment of benign thyroid nodules in 435 patients. Experimental Biology and Medicine 2017; 242: 1515-1523. doi: $10.1177 / 1535370217727477$

[32] Wu W, Gong X, Zhou Q et al. US-guided percutaneous microwave ablation for the treatment of benign thyroid nodules. Endocrine Journal. 2017; 64: 1079-1085. doi:10.1507/endocrj.EJ17-0152

[33] Barile A, Quarchioni S, Bruno F et al. Interventional radiology of the thyroid gland: Critical review and state of the art. Gland Surgery 2018; 7: 132-146. doi:10.21037/gs.2017.11.17

[34] Dossing H, Bennedbaek FN, Karstrup S et al. Benign solitary solid cold thyroid nodules: US-guided interstitial laser photocoagulation - initial experience. Radiology 2002; 225: 53-57. doi:10.1148/radiol. 2251011042

[35] Dossing H, Bennedbaek FN, Hegedus L. Long-term outcome following interstitial laser photocoagulation of benign cold thyroid nodules. European Journal of Endocrinology. 2011; 165: 123-128. doi:10.1530/eje-11-0220
[36] Spiezia S, Vitale G, Di Somma C et al. Ultrasound-guided laser thermal ablation in the treatment of autonomous hyperfunctioning thyroid nodules and compressive nontoxic nodular goiter. Thyroid : Official Journal of The American Thyroid Association 2003; 13: 941-947. doi:10.1089/105072503322511346

[37] Dossing H, Bennedbaek FN, Hegedus L. Long-term outcome following laser therapy of benign cystic-solid thyroid nodules. Endocrine Connections 2019, doi:10.1530/ec-19-0236

[38] Hjermstad M], Fayers PM, Haugen DF et al. Studies comparing Numerical Rating Scales, Verbal Rating Scales, and Visual Analogue Scales for assessment of pain intensity in adults: A systematic literature review. Journal of Pain and Symptom Management. 2011; 41: 1073-1093. doi:10.1016/j.jpainsymman.2010.08.016

[39] Esnault O, Franc B, Menegaux F et al. High-intensity focused ultrasound ablation of thyroid nodules: First human feasibility study. Thyroid: Official Journal of The American Thyroid Association. 2011; 21: 965-973. doi:10.1089/thy.2011.0141

[40] Lang BHH, Woo YC, Chiu KW. Evaluation of pain during high-intensity focused ultrasound ablation of benign thyroid nodules. European Radiology 2018; 28: 2620-2627. doi:10.1007/s00330-017-5200-6

[41] Korkusuz H, Sennert M, Fehre N et al. Localized Thyroid Tissue Ablation by High Intensity Focused Ultrasound: Volume Reduction, Effects on Thyroid Function and Immune Response. RoFo : Fortschritte auf dem Gebiete der Rontgenstrahlen und der Nuklearmedizin 2015; 187: 1011-1015. doi:10.1055/s-0035-1553348

[42] Lang BH, Woo YC, Wong CKH. High-intensity focused ultrasound for treatment of symptomatic benign thyroid nodules: A prospective study. Radiology 2017; 284: 897-906. doi:10.1148/radiol.2017161640

[43] Lang BHH, Woo YC, Chiu KW. Two-year efficacy of single-session high-intensity focused ultrasound (HIFU) ablation of benign thyroid nodules. European radiology 2019; 29: 93-101. doi:10.1007| s00330-018-5579-8

[44] Giovanella L, Piccardo A, Pezzoli C et al. Comparison of high intensity focused ultrasound and radioiodine for treating toxic thyroid nodules. Clinical endocrinology 2018, doi:10.1111/cen.13738

[45] Gharib H, Papini E, Garber JR et al. American association of clinical endocrinologists, American college of endocrinology, and Associazione Medici endocrinologi medical guidelines for clinical practice for the diagnosis and management of thyroid nodules--2016 updatE. Endocrine practice: Official journal of the American College of Endocrinology and the American Association of Clinical Endocrinologists. 2016; 22: 622-639. doi:10.4158/ep161208.gl

[46] Kim JH, Baek JH, Lim HK et al. Summary of the 2017 thyroid radiofrequency ablation guideline and comparison with the 2012 guideline. Ultrasonography (Seoul, Korea). 2019. 38: 125-134. doi:10.14366/usg.18044

[47] Dobnig H, Zechmann W, Hermann M et al. Radiofrequency ablation of thyroid nodules: "Good Clinical Practice Recommendations" for Austria: An interdisciplinary statement from the following professional associations: Austrian Thyroid Association (OSDG), Austrian Society for Nuclear Medicine and Molecular Imaging (OGNMB), Austrian Society for Endocrinology and Metabolism (OGES), Surgical Endocrinology Working Group (ACE) of the Austrian Surgical Society (OEGCH). Wiener medizinische Wochenschrift (1946) 2019, doi:10.1007| s10354-019-0682-2 